\title{
Methemoglobinemia after Local Anesthesia with Prilocaine in a Newborn after Aortic Coarctation Repair: A Case Report
}

\author{
Dilek Altun ${ }^{1 *}$, Adnan Yüksek ${ }^{1}$, Ahmet Arnaz ${ }^{2}$, Yusuf Kenan Yalçınbaş ${ }^{2}$ and Tayyar Sarıoğlu \\ ${ }^{1}$ Department of Anesthesiology and Reanimation, Acıbadem Bakırköy Hospital, Istanbul, Turkey \\ ${ }^{2}$ Department of Cardiovascular Surgery, Acıbadem Bakırköy Hospital, Acıbadem University, Istanbul, Turkey \\ ${ }^{3}$ Department of Pediatric Cardiac Surgery, Acıbadem University, Acıbadem Bakırköy Hospital, Istanbul, Turkey
}

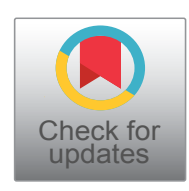

*Corresponding author: Dilek Altun, MD, Acibadem Bakırköy Hospital, Department of Anesthesiology, Halit Ziya Uşaklıgil Street No 1, Istanbul, Turkey, Tel: +902124144444,E-mail: drdilekaltun@hotmail.com

\begin{abstract}
Prilocaine, widely used local anesthetic, can cause methemoglobinemia in pediatric patients even in therapeutic doses. Although complications related to local anesthesia are rare, it may occur especially in pediatric population when used in large doses exceeding the safe limits. Local anesthetic agent oxidizes hemoglobin and may cause methemoglobinemia. Methemoglobinemia manifests with clinical findings such as cyanosis without typical signs of respiratory failure.

In this case report; we present methemoglobinemia that has occured secondary to $2 \mathrm{mg} / \mathrm{kg} \mathrm{2 \%}(6.5 \mathrm{mg})$ prilokaine which was used as intercostal injection for postoperative analgesia for the 3-days-old, 3250 gram, newborn baby who underwent aortic coarctation repair with left thoracotomy. Ascorbic acid was used for the treatment of methemoglobinemia. Physicians using local anesthetics should always keep methemoglobinemia in mind especially in pediatric patients with unexpected cyanosis even after the use of normal doses of local anesthetics.
\end{abstract}

\section{Keywords}

Methemoglobinemia, Prilocaine, Newborn, Postoperative analgesia, Congenital heart surgery

\section{Introduction}

Methemoglobin is the oxidized form of hemoglobin in which the iron in the heme component is oxidized from ferrous (+2) to ferric $(+3)$ state. This renders the hemoglobin molecule incapable of effectively transporting and releasing oxygen to the tissues. Normally, there is about $1 \%$ of total hemoglobin in methemoglo- bin form. A small amount of methemoglobin exists in red cells as a result of normal oxidative functions [1].

Congenital methemoglobinemia occurs due to deficiency of enzymes Nicotinamide Adenine Dinucleotide (NADH) b5 reductase and nicotinamide adenine dinucleotide phosphate flavin reductase. Acquired methemoglobinemia is more common and occurs as a result of oxidising agents such as nitrate, phenytoin, benzocaine, prilocaine, nitric oxide due to overwhelming of capacity of reducing enzymes [1-3].

Symptoms associated with higher levels of methemoglobin are; cyanosis (patients may be relatively asymptomatic), dyspnea, weakness, palpitations, abnormal cardiac rhythms; altered mental status, delirium, seizures, coma, profound acidosis, death.

Cyanosis is caused by methemoglobinemia with raised concentration of methemoglobin in the circulation. Methemoglobin, in contrast to hemoglobin, is unable to transport oxygen, and the remaining hemoglobin is insufficient for oxygen delivery, leading to functional anemia [1-3].

Here, we have presented our experience and successful treatment with ascorbic acid in a newborn with methemoglobinemia due to prilocaine that was used for postoperative analgesia after aortic coarctation repair.

\section{Case Report}

A 3-days-old, 3250 gram newborn was admitted to 
our hospital for aortic coarctation repair. After aortic coarctation repair with left thoracotomy $2 \mathrm{mg} / \mathrm{kg}$ (total $6.5 \mathrm{mg}$ ) 2\% prilocaine (Cytanest 2\%; Astra Zeneca, Istanbul, Turkey) was injected by the surgeon under direct vision into the related intercostal space before left thoracotomy closure. After the operation patient has taken to the Cardiovascular Intensive Care Unit (CICU) and with presssure control ventilation mode $\left(\mathrm{FiO}_{2}: 50 \%\right.$, respiratory rate: $40 / \mathrm{min}$, tidal volume: $10 \mathrm{ml} / \mathrm{kg}$, PEEP: $5 \mathrm{~cm} \mathrm{H}_{2} \mathrm{O}$ ).

During the follow-up in CICU minimal cyanosis was observed at hands and feet in the first hour after admission to $\mathrm{CICU}$. The arterial blood gas analysis revealed $\mathrm{PO}_{2}: 275, \mathrm{SO}_{2}: 99.1, \mathrm{Hgb}: 12.4, \mathrm{Htc}: 38.1$, MetHb: 2.4, $\mathrm{SPO}_{2}: 95$.

His heart rate was $153 / \mathrm{min}$, respiratory rate $40 / \mathrm{min}$, saturation $85 \%$ with a $\mathrm{FiO}_{2} 50 \%$ oxygen with mechanical ventilation, blood pressure $85 / 60 \mathrm{mmHg}$, and he had a temperature of $36.8^{\circ} \mathrm{C}$. Further physical examination was normal.

At the second hour, peripheral cyanosis increased, and there was a mismatch between the peripheral oxygen saturation and arterial $\mathrm{O}_{2}$ saturation. Although we have increased the oxygen level of the patient to $100 \%$ $\left(\mathrm{FiO}_{2}: 100 \%\right)$ there was no improvement in the cyanosis without typical signs of respiratory failure. In the arterial blood samples we could not measure the oxygen level. According to these findings, methemoglobinemia has considered due to the inability to measure the oxygen saturation in the blood and gradual increase in the level of methemoglobin. The methemoglobin level was increased to maximum level of $20 \%$.

A 5\% dextrose solution and a single dose of ascorbic acid (100 mg/kg/iv) were given intravenously. Cyanosis disappeared and $\mathrm{O}_{2}$ saturation started to improve 7 hours after ascorbic acid treatment. Methemoglobin level decreased to $7.2 \%$ at the fourth hour and $2.8 \%$ at the sixth hour of treatment (Table 1 ).

Blood tests were repeated after 24 hours for evidence of hemolysis and rebound methemoglobinemia. She was extubated at the $30^{\text {th }}$ hour of the CICU stay and was transferred to patient floor without complications.

The family was informed about the patient's clinical findings related with methemoglobinemia due to the prilocaine and their consent was taken to publish this case.

\section{Discussion}

This case report represents a 3-days-old newborn baby girl with methemoglobinemia which occured due to intercostal prilocaine infiltration after aortic coarctation repair which was used for postoperative analgesia.

Low levels of arterial oxygen saturation in the arterial blood without cardiac and pulmonary cause is one of the conditions associated with methemoglebinemia $[1,5]$.

Young infants are more susceptible to developing methemoglobinemia because fetal hemoglobin is more easily oxidized than adult-type hemoglobin. Besides, young infants have lower levels of cytochrome-b5 reductase in their red blood cells during the first 4 months of life, resulting in a lower capacity to reduce methemoglobin $[1,5]$.

Predisposing factors for methemoglobinemia include age (infants under 6 months), status of the area being sprayed or injected, concomitant use of other drugs which also have been implicated in causing methemoglobinemia and the genetic make-up of the patient (due to altered haemoglobin, G6PD deficiency or methemoglobin reductase enzyme deficiency). Use of local anesthetic agents in lower doses may be an approach to be followed in this group of patients [4].

Prilocaine is the most potent methemoglobin-forming local anesthetic that can cause methemoglobinemia, even at therapeutic doses especially in children [6-8].

In our patient, 2 hours after the injection of $2 \mathrm{mg} / \mathrm{kg}$ prilocaine, cyanosis with methemoglobinemia became apparent. Grey-blue cyanosis, which is unresponsive to oxygen therapy, is a valuable and only clinical finding especially in patients with mechanical ventilation support [9-11].

Headache, tinnitus, numbness of the lips, dizziness,

Table 1: Postoperative blood sample values and methemoglobin levels.

\begin{tabular}{|c|c|c|c|c|c|c|c|c|c|c|}
\hline & Postop $15^{\text {th }}$ min & $1^{\text {st }}$ hour & $2^{\text {nd }}$ hour & $3^{\text {rd }}$ hour & $5^{\text {th }}$ hour & $7^{\text {th }}$ hour & $8^{\text {th }}$ hour & $10^{\text {th }}$ hour & $24^{\text {th }}$ hour & $48^{\text {th }}$ hour \\
\hline $\mathrm{Ph}$ & 7.39 & 7.49 & 7.50 & 7.55 & 7.51 & 7.41 & 7.49 & 7.44 & 7.41 & 7.41 \\
\hline $\mathrm{PO}_{2}$ & 275 & 204 & 121 & 120 & 152 & 163 & 171 & 159 & 152 & 213 \\
\hline $\mathrm{PCO}_{2}$ & 31.4 & 30 & 29 & 26 & 26 & 27 & 30 & 32 & 35 & 37 \\
\hline $\mathrm{HCO}_{3}$ & 23 & 23 & 24 & 22 & 21 & 17 & 25 & 23 & 24 & 23 \\
\hline $\mathrm{SO}_{2}$ & 99 & 99 & - & - & - & 97 & 98 & 99 & 99 & 99 \\
\hline $\mathrm{SPO}_{2}$ & 95 & 92 & 89 & 90 & 92 & 95 & 99 & 100 & 100 & 100 \\
\hline MetHb & 2.4 & 5.8 & 16 & 19.8 & 20 & 14.5 & 7.2 & 2.8 & 0.9 & 0.5 \\
\hline $\mathrm{FiO}_{2}$ & 50 & 50 & 80 & 100 & 80 & 60 & 50 & 40 & 40 & 35 \\
\hline Lactate & 1.8 & 2.1 & 2.3 & 1.8 & 1.5 & 1.1 & 1.6 & 1.3 & 1.1 & 2.0 \\
\hline
\end{tabular}

Abbreviations: Postop: Postoperative; $\mathrm{PO}_{2}$ : Partial Pressure of Oxygen; $\mathrm{PCO}_{2}$ : Partial Pressure of Carbon Dioxide; $\mathrm{HCO}_{3}: 4$ Bicarbonate; $\mathrm{SO}_{2}$ : Arterial Oxygen Saturation; $\mathrm{SPO}_{2}$ : Pulse Oximetry Saturation; MetHb: Methemoglobin; $\mathrm{FiO}_{2}: 5 \mathrm{Fraction}^{2}$ of Inspired Oxygen. 
lethargy, weakness, confusion, and dyspnea may be observed at higher concentrations of methemoglobin. Respiratory depression, cardiac arrhythmias, convulsion, and coma may occur below a $50 \%$ level, while concentrations above $70 \%$ may be fatal $[11,12]$.

In our patient, intercostal block was performed by using $2 \mathrm{mg} / \mathrm{kg}$, 2\% prilocain (total dose: $6.5 \mathrm{mg}$ ). After the operation patient was taken to the CICU. Two hours later after injection of prilocaine cyanosis appeared at lips, hands and feet. Because our patient was entubated and sedated no other symptoms was observed. The patient, who did not have any additional disease and who previously received local anesthetics, was considered to have acquired methemoglobinemia. Diagnosis was confirmed with arterial blood gas analysis. In literature, it is not specified whether methemoglobinemia is related to the doses of prilocaine. However, the administration of prilocaine may increase the risk of methemoglobinemia $[11,12]$.

Particularly after pudendal anesthesia in obstetrics, there have been several case reports of methemoglobinemia in newborns [13]. According to the other study methemoglobin values did not increase in mothers, and only minimally elevated levels found in newborns. Of the 17 women who had been given pudendal anesthesia with a dose of prilocaine limited to $200 \mathrm{mg}$, symptomatic methemoglobinemia didnot occur [14]. A literature review on methemoglobinemia caused by local anesthetic agents, found a higher risk with the use of prilocaine and benzocaine than with other local anesthetics [7].

Supplementary oxygen therapy is the most important step for the treatment. The use of supplementary $\mathrm{O}_{2}$ increases plasma levels of dissolved $\mathrm{O}_{2}$, contributing, to the improvement of Oxygen Delivery $\left(\mathrm{DO}_{2}\right)$ and Oxygen Consumption $\left(\mathrm{VO}_{2}\right)$ during tissue hypoxia. Hyperoxic pulmonary ventilation (inspired fraction of $\mathrm{O}_{2}$ of 1.0) can accelerate the degradation of MetHb and prolong the survival of pigs submitted to lethal acute MetHb $[14,15]$.

After operation, peripheral cyanosis appeared one hour after admission to $\mathrm{CICU}$, and there was a mismatch between the arterial blood oxygen saturation and the peripheal oxygen saturation. Although we increased the level of oxygen, cyanosis did not improve.

After $1 \mathrm{~h}$ of oxygen treatment methemoglobin concentration was $16 \%$ and continued to increase to the maximum level of $20 \%$ at the $5^{\text {th }}$ hour.

Intravenous methylene blue is the first agent of choice; however, there are some studies where ascorbic acid was used for the treatment of methemoglobinemia [7]. Since intravenous of methylene blue was not available, we have used ascorbic acid for the treatment of methemoglobinemia. Three hundred mg IV ascorbic acid was slowly administered in $24 \mathrm{~h}$. After $1 \mathrm{~h}$, oxygen saturation began to increase and 2 hours later normalised. Methemoglobin levels were $20 \%$ before ascorbic acid administration. After 24 hour of administration, methemoglobin level was $0.9 \%$ [12-15].

Methemoglobinemia can easily be missed in children due to the presence of accompanying respiratory problems. Therefore, a high level of suspicion is necessary in cases with unexplained cyanosis after local anesthesia that is unresponsive to oxygen therapy. When this occurs, the early recognition of methemoglobinemia can prevent tissue hypoxia.

We also believe that intravenous ascorbic acid, the treatment of choice for our patient, should be readily available and that prilocaine, even at low doses, should be used with caution.

There is no conflict of interest to declare as this study is not industry sponsored and we did not receive financial support for research and analysis. Signed documents declaring no conflict of interest and copyright transfer forms are enclosed.

\section{References}

1. Wright RO, Lewander WJ, Woolf AD (1999) Methemoglobinemia: Etiology, pharmacology, and clinical management. Ann Emerg Med 34: 646-656.

2. Couper RTL (2000) Methaemoglobinaemia secondary to topical lignocaine/prilocaine in a circumcised neonate. J Paediatr Child Health 36: 406-407.

3. Ozdogan H, Osma S, Aydin GB, Avni Dinc, Gulten Ozgun (2010) Methemoglobinemia presenting in a circumcised baby following application of prilocaine: A case report. $\mathrm{J}$ Med Case Rep 4: 49.

4. Boran P, Tokuc G, Yegin Z (2008) Methemoglobinemia due to application of prilocaine during circumcision and the effect of ascorbic acid. J Pediatr Urol 4: 475-476.

5. Sivasli E, Gursoy T, Yurdakok M (2005) Which local anesthesia should be used in neonatal circumcision in newborns? Saudi Med J 26: 690-691.

6. Mutlu M, Erduran E, Aslan Y (2011) Acquired Methemoglobinemia in Infants. Turk J Hematol 28: 131-134.

7. Guay J (2009) Methemoglobinemia related to local anesthetics: A Summary of 242 Episodes. Anesth Analg 108: 837-845.

8. Hahn RT, Abraham T, Adams MS, Charles J Bruce, Kathryn E Glas, et al. (2014) Guidelines for performing a comprehensive transesophageal echocardiographic examination: recommendations from the American Society of Echocardiography and the Society of Cardiovascular Anesthesiologists. Anesth Analg 118: 21-68.

9. Caner I, Ziraatçi Ö, Taştekin A (2011) Methemoglobinemia Due To Prilocaine Which Treated With Oral Methylene Blue. Turkish J Pediatr Dis 5: 172-176.

10. Kuiper-Prins E, Kerkhof GF, Reijnen CG, Van Dijken PJ (2016) A 12-Day-Old Boy with Methemoglobinemia After Circumcision with Local Anesthesia (Lidocaine/Prilocaine). Drug Saf Case Rep 3: 12.

11. Tran AN, Koo JY (2014) Risk of systemic toxicity with topical lidocaine/ prilocaine: A Review. J Drugs Dermatol 13: 1118-1122. 
12. Gülgün M, Kul M, Sarıcı SU, Alpay F (2007) Prilocine-induced methenoglobinemia: report of two cases and review of literature. Erciyes Medical Journal 29: 322-325.

13. Uslu S, Comert S (2013) Transient neonatal methemoglobinemia caused by maternal pudendal anesthesia in delivery with prilocaine: report of two cases. Minerva Pediatr 65: 213-217.
14. M Kirschbaum, J Biscoping, B Bachmann, W Künzel (1991) Fetal methemoglobinemia caused by prilocaine--is use of prilocaine for pudendal block still justified? Geburtshilfe Frauenheilkd 51: 228-230.

15. Vidyarthi V, Manda R, Ahmed A, Khosla S, Lubell DL (2003) Severe methemoglobinemia after transesophageal echocardiography. Am J Ther 10: 225-227. 